Anales de Literatura Hispanoamericana

ISSN: 0210-4547

http://dx.doi.org/10.5209/alhi.66792

\title{
El fantasmagórico horror de lo banal o La primera vez que vi un fantasma
}

Vicente Cervera Salinas ${ }^{1}$

Resumen. Este artículo realiza un recorrido por los relatos que integran el volumen de la escritora ecuatoriana Solange Rodríguez Pappe, La primera vez que vi un fantasma, publicado en 2019. Los cuentos se insertan en una doble tradición: la europea y la propiamente hispanoamericana, donde los nombres de Miguel Ángel Asturias y Juan José Arreola resultan determinantes para la activación de los recursos simbólicos y temáticos propios de la esta reciente narrativa de lo fantástico o, según nuevos catálogos críticos, de lo "inusual".

Palabras clave: cuento; literatura ecuatoriana; literatura femenina; fantasía; Solange Rodríguez Pappe.

\section{[en] The ghostly horror of the banal or La primera vez que vi un fantasma}

\begin{abstract}
This paper analyzes the tales or short stories that integrate the volume of Ecuadorian writer Solange Rodríguez Pappe, La primera vez que vi un fantasma, published in 2019. The stories are inserted in a double tradition: the European and the Spanish-American itself, where the names of Miguel Ángel Asturias and Juan José Arreola are decisive for the activation of the symbolic and thematic resources of this recent narrative of the fantastic or, according to new critical catalogs, of the "unusual."
\end{abstract}

Keywords: tale; Ecuadorian literature; female literature; fantasy; Solange Rodríguez Pappe.

Cómo citar: Cervera Salinas, V. (2019) El fantasmagórico horror de lo banal o La primera vez que vi un fantasma, en Anales de Literatura Hispanoamericana 48, 425-433.

El breve relato "La migala" del mexicano Juan José Arreola se ha convertido por derecho propio es un texto paradigmático de la literatura de las últimas décadas, cumplido ya su más de medio siglo de existencia. Y lo es por su cualidad insólita, a caballo entre lo bizarro y lo perverso, con su confesión inacabada en primera persona de una historia donde Eros y Tánatos se unen y el elemento fantástico se brinda en una cruel metamorfosis, decidida por el propio protagonista del texto: transformar su Beatriz en una repulsiva tarántula (Lagmanovich 1977: 426). En un momento determinado de la narración puede leerse: "Dentro de aquella caja iba el infierno personal que instalaría en mi casa para destruir, para anular al otro, al descomunal infierno de los hombres". Y ya dueña del espacio, confiesa el narrador:

1 Universidad de Murcia, Murcia. España.

E-mail: vicente@um.es 
"Se pasea embrolladamente por el cuarto y trata de subir con torpeza a las paredes. Parece husmear, agitada, un invisible compañero." (Arreola 1980: 24-25). En el mítico relato del Confabulario arriolano, "La presencia del modelo dantesco actúa como soporte de un mecanismo de idealización ya imposible, en un mundo donde el tiempo se ha derrumbado y los paraísos prometidos han sido sustituidos por los tan temidos infiernos." (Cervera 2006: 267).

La atroz pesadilla de evidentes resonancias kafkianas (Romanek 1981) que se relata en esta breve historia también parece husmear en la actual narrativa de terror, fantástica o de lo insólito e inusual escrita fundamentalmente por mujeres, que puebla los catálogos de las novedades editoriales en español. Nombres de escritoras nacidas a partir de los años sesenta y que, como bien ha señalado Carmen Alemany (2018: 10), "han publicado sus principales obras en el siglo XXI" como las mexicanas Daniela Tarazona, Adriana Díaz Enciso o Cecilia Eudave; las argentinas Samanta Schweblin o Mariana Enríquez, la peruana Claudia Ulloa y las ecuatorianas María Fernanda Ampuero y Solange Rodríguez Pappe. La mayoría de ellas combina la escritura de novelas y cuentos, y muchas compaginan la actividad creativa con la docente, en muchos casos universitaria, como es el caso de Solange. Algunas han sido incluidas en el reciente volumen Insólitas. Narradoras de lo fantástico en Hispanoamérica y España, editado este año 2019 por Páginas de Espuma, como la propia Rodríguez Pappe con su breve relato "Pequeñas mujercitas", también incorporada en la reciente colección La primera vez que vi un fantasma.

Es curioso y bastante notable que haya una cierta concordancia en la elección de un género, como el fantástico con sus múltiples variaciones, por parte de otro género, como es el femenino (también con sus no menos múltiples diferencias) y dentro de un corte generacional más o menos parejo. Lo cierto es que hay una tendencia en la narrativa actual desde lo femenino hacia lo fantástico (proteico, en todo caso), con especial hincapié en el género breve (sin descartar por ello la escritura de novelas, o de novelas episódicas, a modo de fragmentos casi independientes) e incluyendo casi siempre la hibridez genérica. Como maestros, también se apunte a los grandes narradores europeos y americanos (anglo e hispanoamericanos) de los siglos XIX y XX.

Todo esto queda bien plasmado en la colección de cuentos publicado en 2018 por la editorial Candaya de Solange Rodríguez Pappe, La primera vez que vi un fantasma, compilación con la que su obra se ha consolidado en el ámbito de la narrativa contemporánea no sólo en su país natal, Ecuador, sino también en el ámbito español, tas la extraordinaria acogida de colecciones previas como Balas perdidas (2010) o La bondad de los extraños (2016). Así, en el cuento "Matadora" de su última entrega, uno de los más certeramente femeninos y aun feministas de la colección, también impera la empoderada figura de un animal de sexo femenino sobre el degenerado espectro de un mundo -masculino- oscuro y yermo. La sombra de la migala parece reconocerse también aquí, una presencia que se asimila a la ya canonizada por la tradición romántico-simbolista, a través de la literatura trasatlántica, en este caso la que vincula la norteamericana de Edgard Allan Poe con la francesa de Charles Baudelaire y la del conde de Lautréamont con Marcel Schwob. Así, por ejemplo, en "Aracne" del Corazón doble de Schwob se percibe la huella del motivo deletéreo amoroso (Cervera, ibid.), que llega hasta las páginas 
del mexicano y, desde las suyas, hasta la de estas narradoras de lo "insólito" (Alemany, ibid.), como en este de "Matadora": "Después de esa noche, no hemos vuelto a tener ningún problema con la Junta de Vecinos. A la una de la madrugada, corren sus cerrojos y sus trancas y se agazapan en sus camas, cubriéndose, en absoluto silencio. Entonces la gata se pasea a gusto por todos los pisos, husmeando si hay algo interesante bajo las puertas. Poco a poco, junto a su camada, ha ido ampliando sus excursiones más allá de los Cerros" (2018: 101).

Y en el cuento intitulado "La historia incómoda que nos contó Olivia el día de su cumpleaños", somos lectores implícitos de un suceso narrado en el ámbito festivo de ese cumpleaños que impregna con su desazón lo monstruoso y fantasmático. Se nos dice así (como si fuésemos presencia viva en la celebración de Olivia también nosotros, los lectores): "Y cuando había tiempo libre ponía cosas en el buscador de internet sobre apariciones y ciudades, y la conclusión básicamente era que todas las ciudades están construidas sobre huesos y cementerios, así que, de cada cinco habitantes, uno es un fantasma." (2018: 79). Y añade una acotación entre paréntesis, pues el cuento está escrito como si de un monólogo teatral se tratase donde sólo esos paréntesis se hurtan a la voz del personaje: "(Mira intentando descubrir a uno entre el público)" (ibíd.). Por supuesto, se trata de divisar a uno de esos fantasmas que se multiplican en nuestro mundo y a los que Rodríguez Pappe rinde tributo y honor en su libro. No es extraño, parece transmitirnos, que antes o después seamos capaces de ver a uno de ellos.

En general, el mundo que retrata o, mejor, en que se desarrollan las fabulaciones y ficciones de la escritora guayaquileña, tiene mucho que ver con un universo en descomposición, muy poco habitable (bien por el extremo calor en que transcurren muchas de las ficciones o bien por la penuria moral o la frivolidad macabra de sus moradores). Calor asfixiante y penuria moral son la atmósfera que desprenden y destilan la mayoría de estos cuentos que en ocasiones parecen ilustrar la recordada tesis de Hanna Arendt sobre la "banalidad del mal" -a propósito del caso del caso Eichman y su colaboración con el genocidio nazi-. Banalidad del mal en el sentido de que estas ficciones también retratan la ausencia de reflexión o de pensamiento generalizados que condiciona un modus operandi donde el mal prolifera, como los hongos sobre la superficie de la tierra (Arendt 1999). No es un mal con dimensión demoníaca o sobrenatural sino un mal que se extiende sin hondura en la superficie de las cosas. Así el cuento "Un paseo de domingo" tiene el siguiente arranque: "Como ocurre en toda familia normal, suelo salir de paseo con mi madre las tardes de domingo. Hacemos juntas el trayecto en auto, mirando por la ventana cómo ha cambiado el paisaje urbano que va del centro al norte, los espacios de los árboles talados que van transformando nuestra ciudad en un pozo caliente" (2018: 70). Ese pozo caliente simboliza el fondo en que se transita en un lento pero seguro proceso de hundimiento, muchas veces imperceptible, que asimismo contamina la mirada y las acciones cotidianas de los personajes que en él se sumen día tras día. Los fantasmas son las percepciones lúcidas de esa realidad invivible y demoledora.

También sus relatos evidencian un mundo donde puede prevalecer lo raro, lo estrambótico o estrafalario, lo siniestro o lo perverso. La era de los internautas se amalgama y funde a modo de simbiosis con el culto a lo desaforado y excesivo, a lo disparatado como expresión suprema de los credos más oblicuos, como sucede con la boda de la hermana de la protagonista del cuento "Un hombre en mi cama", 
que celebra sus nupcias con un árbol, una acacia concretamente, "para demostrar la necesidad de tener más responsabilidad ambiental" (2018: 53). Esa exageración o desmesura en las voluntades, que roza el frikismo y el delirio, parece no encontrar límites ni cortapisas en los relatos de Solange, como expresión señera de un mundo también desaforado y banal. Así, en el mismo cuento la voz narrativa nos confiesa que "Después de la boda, algunos periodistas independientes que habían estado esperando a que terminaran los vítores y las felicitaciones a la novia, se acercaron, con filmadoras y micrófonos, a hacer entrevistas a los invitados y conocer su opinión sobre las boas con objetos, para un canal especializado en el tema." (ibid.: 55). La protagonista, por su parte, pertenece a un grupo de internautas que suben fotos y vídeos a un portal común donde se exhiben cuerpos de bellos y bellas durmientes, en una atmósfera pre-apocalíptica que, al mismo tiempo, exhibe signos y rituales ya presentes en la era de Internet, donde los lectores actuales nos reconocemos y, al mismo tiempo, vislumbramos las consecuencias de ese mundo presente y ya futuro.

Asimismo, en "Paladar", uno de los más intensos de sabor de toda la colección, la pareja protagonista compensa el aburrimiento de una existencia anodina, una suerte de perenne y eufemística convalecencia, con excursiones donde el reclamo de la comida alcanza grados que son, progresivamente (como gustaba a Edgard Allan Poe) más perversos y macabros. Que el "amor es una suerte de canibalismo", como reza la cita inicial de Patricia Esteban Erlés, que sirve a Solange de paratexto (2018: 16) a su relato, parece ir confirmándose en este enigmático cuento, de un expresionismo crudo y visceral, donde los ensayos de Georges Bataille parecen imbricarse con la apuesta por el efecto de sorpresa, tan consustancial al cuento como género, tal como decretara famosamente el ya citado Poe. La enfermedad que padece la protagonista y narradora del cuento subraya el efecto de descomposición que afecta a la vida y al ocio de la pareja, y que mide su hundimiento creciente en lo macabro, traspasado por el signo de lo "crudo" y "visceral" -también en la misma clave de Bataille-, que asoma en la sub-trama amorosa del cuento, donde al fin se aglutinan y digieren de nuevo los vínculos entre Eros y Tánatos, pero modulados por el signo de los tiempos. Un signo donde impera la trivial disolución de la materia. Como sucedía en el "Almohadón de plumas", de Horacio Quiroga, la trama real de la historia representa una parábola de la trama subyacente: si en el cuento de Quiroga el "largo escalofrío" (Quiroga 1985:1) que había producido la "luna de miel" a la protagonista femenina del cuento, Alicia, quedaba representada en la línea argumental de su enfermedad, producida por la succión de un animal vampírico entre las plumas del almohadón donde recostaba cada noche su cabeza, en esta ficción de Rodríguez Pappe el deterioro corporal que va minando la saludo de la narradora es manifestado en la degeneración reconocible en su vida matrimonial y en la aniquilación fatal que digiere la breve e intensa historia de amor imposible en que se verá sumergida.

Un mundo, en fin, el de los relatos de Rodríguez Pappe que se asoma vertiginosamente al apocalipsis, como sucede en "Confeti en el cielo", cuya primera frase contiene en sí el germen total de su espléndido desarrollo, tal como decretara también en su día Quiroga en su conocido "Decálogo del perfecto cuentista": "No empieces a escribir sin saber desde la primera palabra donde vas. En un cuento bien logrado, as tres primeras líneas tienen casi la misma importancia 
que las tres últimas" (Quiroga 1985: xxxiv). Así leemos en el íncipit del relato: "Decidí pasar la última noche de la tierra en el sillón de la sala, arrullada por la luz de las fogatas públicas que habían empezado a proliferar desde que se agotó la electricidad." (2018: 119). Este cuento, uno de las logrados y "perfectos" -en sentido quiroguiano precisamente- de la colección, nos habla de esas "muertes cotidianas" que van pautando el escenario de una noche última y final, y en él se propaga la amorosa sombra de Julio Cortázar que ve extendida su visión de una casa tomada a la de otra toma, mucho más feroz y despiadada en la versión de Solange, pues se trata ahora de la toma del mundo, no la de un solo hogar. "Entonces sucedió: el temblor y la ceniza se esparcieron por el aire, golpeándonos como un escupitajo tenso. No volvimos a abrir los ojos. La mano de Santiago" -nos dice la narradora- "buscó mi mano: la apretó con firmeza y yo puse mi frente en su pecho, para siempre.” (125). ¿Cómo no pensar en el narrador del cuento de Cortázar saliendo con su hermana Irene de la casa de los ancestros y arrojando -con temor y temblor- la llave por el hueco de una alcantarilla, para siempre?

Paraísos perdidos, como el del último relato que le da título a la colección, "La primera vez que vi un fantasma", en el que la presencia del cine es asimismo relevante: los cines de motel y de apartamentos donde deslumbra la soledad (Paris/Texas de Wim Wenders; Mulholland Dirve, de David Lynch e incluso la imborrable Psicosis). Precisamente será Las Vegas la ubicación del texto de Rodríguez Pappe, y la narradora va introduciendo signos denotativos de esa cualidad macabra y desasosegante que puebla el espacio, donde se subraya insistentemente en la no existencia de fantasmas en las piezas del hotel. Así, la protagonista, reflejada en uno de los vidrios del gigantesco salón, se descubre "espantosa", suponiendo así que "Nadie podría sospechar que alguien me amara" (2018: 126). Parejamente, la fealdad rodea todos los detalles y elementos del lugar, del destino: "En el lobby del hotel, que en realidad era un cubo feo lleno de luces, había una exposición privada donde se mostraban armas y otros objetos de colección, algo que ellos habían llamado Pequeño Museo Norteamericano de la Muerte". La narradora anota a continuación: "A lo lejos, alcancé a distinguir una ametralladora, la placa agujereada de un carro, la camisa ensangrentada de un hombre hecha jirones.

-¡Qué macabro! -exclamé" (ibid.: 127).

Todo ello va preludiando el apoteósico desarrollo y muy conseguido cierre del volumen -y de la colección toda-, cuando la narradora va tomando posesión de su espacio auténtico, de su soledad absoluta, en el mismo momento en que tiene lugar la revelación, la epifanía: "Y allí estaba, en la oscuridad de mi habitación, quieto, muy nítido, frente a la puerta. Y entonces sí tuve la absoluta certeza de que lo vi." (ibíd: : 138).

Y en torno a este modelo cronotópico del hotel -propio de la tradición fantástica, pero tampoco ausente en la actualizada por las narradoras de lo "inusual"-, florecen parejos los laberintos de la reminiscencia, como el que recorren las voces del primer cuento del volumen, también ubicado en un hotel tras un terrible accidente, y que siempre sucede "A tiempo para desayunar": "Judy es de la nuevas" -nos aclara hacia el final del cuento la voz narrativa- "de las que 
creen que puede haber salida para el laberinto de la reminiscencia. Cuando me pregunta si la recuerdo de algún lado, ensayo una respuesta diferente a lo que decimos todos en esta casa desde que tengo memoria. Le digo que sí, que se me hace conocida. Entonces ella sonríe y me muestra sus encías secas, empastadas de comida, y sin dientes." (2018: 14-15). Como cabe advertir, de nuevo asoma el amargo sabor de lo sórdido y degradado, envuelto en el denso halo de la memoria desovillada y perdida, deshilachada y enflaquecida. Laberinto mental o laberinto del espíritu, la simbología de Rodríguez Pappe hace escala también en los anudamientos propios de los lazos de sangre, estrangulados en sus propios enredos de problema insolubles, como en el que se ve envuelta la familia de la narradora de "El Atanudos", que no en vano se llama Ariadna y que, por ello, no de modo inocente tendrá en su mano el "hilo" para salir ella y los suyos de dicha maldición arquetípica.

Hablando precisamente de este cuento, sería oportuno comentar la progenie del tratamiento de la fantasía en Solange Rodríguez Pappe, que por un lado entronca con esa línea del fantástico psicológico (no visionario) que Italo Calvino derivó de la literatura mentalista de Henry James, y en donde la experiencia rara es metáfora de una realidad tal vez más perturbadora que el suceso incomprensible (como en el ya comentado "El almohadón de plumas" de Horacio Quiroga) pero por otro lado, como muy bien ha reconocido nuestra autora en diversas entrevistas (Rodríguez Pappe 2019: s/p), no puede desligarse de la herencia propiamente hispanoamericana. Italo Calvino señala que "Los fantasmas de las ghost stories de Henry James son muy evasivos: puede tratarse de encarnaciones del mal sin cara y sin forma [...] o apariciones bien visibles que dan forma sensible a un pensamiento dominante" (Calvino 1985: 52). Evasivos, cabría afirmar, como los que aparecen en el volumen de Solange Rodríguez Pappe. Y no sólo sería factible nombra la herencia que, aun forjada en los países hispanoparlantes de América, llegó a ellos desde la literatura europea o norteamericana (descendientes al cabo de E. T. A. Hoffmann, Marcel Schwob, Giovanni Papini, Edgar Allan Poe o Franz Kafka en los cuentos fantásticos de Jorge Luis Borges, Adolfo Bioy, Cortázar, Juan José Arreola o incluso el también ecuatoriano Pablo Palacio), como sería previsible. En el caso de nuestra narradora sería necesario acudir simultánea y complementariamente a la tradición del fantástico, o de lo maravilloso: la genuinamente latinoamericana.

Así sucede precisamente con el cuento "El Atanudos", que es posible emparentar con una de las más conseguidas leyendas guatemaltecas de Miguel Ángel Asturias -cuya primera edición data de 1930, editada precisamente en España, como los cuentos de la ecuatoriana-. Me refiero así a la "Leyenda del Cadejo" (que hace nudos en las crines de los caballos y en las trenzas de las jóvenes), precisamente en la preeminencia del personaje que causa estragos usando para ello lo trenzado o anudado. Recordemos que el escritor guatemalteco inicia su relato folklórico-vanguardista con la reproducción del motivo popular, conservado durante siglos, que llega hasta su modulación particular: “... Y asoma por las vegas el Cadejo, que roba mozas de trenzas largas y hace ñudos en las crines de los caballos..." (Asturias 1995: 105).

Con el motivo del "Cadejo" (versión guatemalteca) o del "atanudos" nos encontraríamos en suma ante la presencia de un mitema. Un mitema que hallamos 
en diversas culturas y con expresiones literarias tan relevantes como la del propio William Shakespeare, en su descripción de la reina Mab en Romeo y Julieta. En el caso de la leyenda de Miguel Ángel Asturias, el mito está en función de recrear la génesis de un personaje popular, ubicando para ella la secuencia narrativa en la época colonial centroamericana, en un convento donde la novicia Elvira de San Francisco va a contraer el hábito de monja en el convento guatemalteco de la Concepción. Esa misma tarde un personaje vinculado al ámbito popular, el hombre-adormidera, tentará su condición de mujer -representada en la trenza que todavía conserva sus atributos femeniles- ocasionando así la formación del Cadejo: este surge en el momento en que la novicia decide sajar su trenza y ésta, de súbito animada mágicamente como serpiente que repta por el suelo, estrangulará al hombre-adormidera y fijará para siempre la figura del mito, aquel que "roba mozas de trenzas largas y hace ñudos en las crines de los caballos": "el hombreadormidera arrastró al infierno la trenza negra de la novicia que con el tiempo sería la madre Elvira de San Francisco -así nace el Cadejo-, mientras ella soñaba entre sonrisas de ángeles, arrodillada en su celda, con la azucena y el cordero místico." (Asturias 1995: 109). En el relato de Solange Rodríguez Pappe, por su parte, hallamos, en las dos partes del relato, la formación del personaje y su perduración posterior en el tiempo, a modo de maldición transfamiliar: "No tengo idea de cómo se llama realmente el ser al que yo me referiré" -se nos informa al comienzo de la historia- "pero en mi familia hemos decidido ponerle un nombre genérico: el Atanudos, pues hace precisamente eso: crea nudos enormes, incomprensibles, y se dedica también a ver cómo perdemos el tiempo desatándolos." (2018: 105).

Pero también "El Atanudos" se vincula explícitamente con la contraposición cortazariana entre los "lados" de la realidad que separan metafísicamente también a los seres, como sucede en "Casa tomada", donde también cabría remitir al fenómeno del tejido, que representa simbólicamente al personaje de Irene-Aracne, que verá al final de su historia como el ovillo que teje quedará en la parte de "allá" de una casa ya definitivamente "tomada". Pero también reconocemos en el cuento el tópico del objeto (o incluso el sujeto) que circula de mano en mano con su carga maldita y heredada, como "El libro de arena" o "La memoria de Shakesperare" de Borges. Este motivo se encuentra también en el célebre relato de terror de principios del XX "La pata del mono", escrito por el humorista "dramático" W.W. Jacobs. Precisamente será Borges quien argumente que al margen de la diversa textura y naturaleza de un relato fantástico (al margen de que se trate de un argumento donde el elemento extraño surja como la excepción a los hechos o que sea la apariencia general donde se desarrollan los mismos), lo importante es que "el resultado sea feliz", recordando siempre que la literatura fantástica es "la más antigua" pues "empieza por la mitología, la cosmogonía" y sólo tardíamente llega a la novela y al cuento (Borges 1985: 25).

El feliz resultado, cabría colegir, de cuentos como "El Atanudos" confirma la hipótesis borgeana y, de algún modo, explicita una de las caras del fenómeno de la fantasía que el argentino postula: un argumento donde el elemento extraño surge como excepción a la generalidad, en este caso la presencia de Atanudos, como generador de inquietud en un ambiente normalizado: la inquietud de lo insólito, cabría recalcar, kafkianamente hablando. No resulta baladí recordar en este sentido que Solange Rodríguez Pappe combina su faceta de escritora con la de profesora 
universitaria y coordinadora de talleres de escritura, y que su trayectoria como narradora no comienza en absoluto con este libro sino que más bien, cabría decir, culmine en el mismo, pues títulos como Tinta de sangre, Dracofilia, El lugar de las apariciones, La bondad de los extraños o Levitaciones, la han convertido en una de las escritoras más destacadas de la joven literatura ecuatoriana del nuevo siglo, sobre todo a partir de la obtención del Premio Nacional Joaquín Gallegos Lara en 2010 por el ya mencionado volumen Balas perdidas.

Una cualidad interesante de La primera vez que vi un fantasma es su componente heterogéneo. Esta diversidad se muestra en el plano de la narración, donde se combinan los personajes narradores con las terceras personas e incluso el parlamento a modo de monólogo dramático, como en el concerniente a la extensión, pues relatos brevísimos, verdaderas pequeñeces como "Cuento antes de ir a la cama" o "Pistola cargada", conviven en la colección con relatos bastante extensos, como "Un hombre en mi cama" o "Paladar". La variedad atañe de modo similar y complementario a la fenomenología temática, pues incluso el leitmotiv del fantasma aparece de modo diverso: como trasunto de una personalidad o como aparición metafórica de una experiencia paralela (Rodríguez Pappe 2019). En el primer caso tendríamos ejemplos como "Pequeñas mujercitas", relato donde el plano femenino vuelve a ser reivindicado como experiencia generadora de una realidad alternativa, por lo que la narradora femenina concluye con su particular venganza, sirviéndose de esos pequeños seres fantásticos, en la figura de su hermano. El cuento vendría a fungir como una parodia invertida precisamente de la "Casa tomada" (aún más allá de la evidente parodia del título de la célebre novela decimonónica y puritana de la norteamericana Louisa May Alcott), como cabría reconocer en su conclusión: "Sin hacer ruido tomé de la mesita las llaves de su coche, mientras más y más mujercitas despelucadas y feroces llegaban a revisar el estado de su nueva colonia. Cuando cerré la puerta y eché doble llave atrancando la salida, me pregunté si los gemidos de mi hermano, que alcancé a escuchar del otro lado del dintel, serían de dolor o de placer." (2018: 66). En efecto, la duda, la incertidumbre, el traspaso de la acción al hermano y el hecho de concluir con la puerta cerrada revelan esa categoría intertextual, pero también la clave hermenéutica del argumento.

La multiplicidad heterogénea de la colección, en fin, concierne al espacio semántico y simbólico también, pues no todos los textos participan de una visión nihilista y preapocalíptica de la sociedad contemporánea, y algunos vínculos humanos parecen emerger con un valor añadido tras la lectura de las tramas. Así sucede con las relaciones entre madre e hija, tal como nos las presenta Solange en cuentos como "Un paseo de domingo" o "Matadora", relato en que la fuerza de las hembras, y en especial de la gata Leona, en la realidad textual deniega el bajo continuo de ese mal banalizado que tiene como víctima el mismo cuerpo femenino. En este sentido el motivo familiar traspasa su corteza crítica y nihilista para establecer, también a través de la categoría de lo insólito, una nueva dimensión simbólica. El mundo líquido que gobierna y aureola el espíritu de la realidad retratada en los relatos de Rodríguez Pappe hallaría, así, un reducto de paradójica solidez, de peso específico y gravedad, mediante la atracción en el plano de los sentimientos y las emociones de los vínculos humanos, prioritariamente los que "anudan" el corazón de las hembras y de los vínculos materno-filiales. 
"Toda historia de amor es una historia de fantasmas", sostuvieron Christina Stead y David Foster Wallace "con 10 años de diferencia", según consta en la cita paratextual con que la editorial Candaya presenta la colección de textos de Solange Rodríguez Pappe (2018: 7). Así es; prácticamente todos ellos podrían corroborar sin restricciones el aserto: historias de amor "vertidas" en el molde de lo fantasmal, de lo insólito, de lo preapocalíptico, del mundo banal y maldito que nos ha tocado vivir en estas primeras décadas del siglo XXI. Quince relatos que convierten a el volumen La primera vez que vi un fantasma en un título totalmente recomendable para amantes de esa literatura que viste el realismo de extrañeza y bizarría para enfatizar precisamente su banalidad y horror (la banalidad de su horror): para abrirnos los ojos no tanto ante la presencia de lo fantástico en nuestra vida -como quisieron Cortázar o García Márquez- sino ante la emergencia de otra certeza que, en cambio, sí está ligada a la línea histórica que conecta a Franz Kakfa con el mexicano Juan José Arreola y su "migala", aunque renovada, claro está, por los signos convulsos y azarosos de nuestros tiempo: la certeza de hallarnos en un modelo de vida muchas veces desvaída y gris, que prefiere y necesita visualizar a sus fantasmas para caer así en la cuenta de su más cruda realidad.

\section{Referencias bibliográficas}

Alemany, Carmen. Prólogo a Cecilia Eudave: Bestiaria vida. León: Eolas ediciones, 2018, pp. 7-21.

Arendt, Hanna. Eichmann en Jerusalén. Trad. Carlos Ribalta. Barcelona: Lumen, 1999.

Arreola, Juan José. Confabulario personal. Barcelona: Bruguera, 1980.

Asturias, Miguel Ángel. Leyendas de Guatemala. Ed. de Alejandro Lanoël. Madrid: Cátedra, 1995.

Borges, Jorge Luis, "Coloquio", en Literatura Fantástica. Madrid: Siruela, 1985, pp. 1336.

Calvino, Italo, (1985): "La literatura fantástica y las letras italianas", en Literatura Fantástica. Madrid: Siruela, 1985, pp. 37-56.

Cervera Salinas, Vicente. El síndrome de Beatriz en la literatura hispanoamericana. Madrid-Frankfurt: Iberoamericana-Vervuert, 2006.

Cortázar, Julio. Bestiario. Barcelona: Alfaguara, 1982.

Quiroga, Horacio. Cuentos. Ed. Raimundo Lazo. México: Porrúa, 1985.

Lagmanovich, David, "Estructura y efecto en La migala de Juan José Arreola", Cuadernos Hispanoamericanos, 320-321, 1977, pp. 419-427.

Romanek, Thomas J., "Kafka's influence in Juan José Arreola", Revue des Langes Vivantes 37, 1981, pp. 305-308.

Rodríguez Pappe, Solange. La primera vez que vi un fantasma. Barcelona: Candaya, 2018.

- "El ser humano convive con lo fantástico desde siempre". Disponible en: https://www.eldiario.es/murcia/cultura/humano-convive-fantasticosiempre_0_876663196.html 